\title{
Elektrik Dağıtım Şebekelerinde Scada/Dms Sistemlerinin İncelenmesi ve Uygulanması
}

\author{
Mehmet YURDABAK ${ }^{1}$, Mustafa ŞEKKEL $\dot{I}^{2}$ \\ ${ }^{1}$ Akedaş Elektrik Dağıtım A.Ş. Kahramanmaraş, Türkiye \\ ${ }^{2}$ Kahramanmaraş Sütçü İmam Üniversitesi, Elektrik Elektronik Mühendisliği, Kahramanmaraş, Türkiye
}

ÖZET: Dünyada her geçen gün enerjiye olan talebin artması elektrik şebekelerinin genişlemesine sebep olmaktadır. Dünyada enerji sektöründeki teknolojik gelişmeler, kaliteli enerji kullanmak için ülkemizde de ön plana çıkmaya başlamıştır. Bunların başında elektrik dağıtım şebekelerinde SCADA/DMS uygulamaları gelmektedir. Elektrik dağıtım şirketlerinin en önemli işlevlerinden bir tanesi, arıza yerini en kısa sürede bulmak ve arızayı onarmaktır. Fakat arıza servislerinin uyguladığı klasik yöntemler kesinti süresini uzattığı gibi tehlike ve zararlar da meydana getirebilmektedir. Bu sebeple elektrik enerjisinin üretiminden tüketimine kadar SCADA/DMS gibi otomasyonel çözümlere ihtiyaç duyulmaktadır. Bu çalışmamızda bir dağıtım şirketimizde uygulaması yapılacak olan SCADA/DMS sistemi genel bir şekilde ele alınacaktır. Bununla birlikte elektrik dağıtım şebekesinin uzaktan izlenmesi, analiz edilmesi ve kontrol edilmesi konularına değinilecektir.

Anahtar Kelimeler: SCADA/DMS sistemleri, Elektrik Dağıtım Şebekesi, Kesinti süresi, Uzaktan izleme

\section{Implementation and Evaluation of SCADA / DMS systems at Electrical Distribution Networks}

\begin{abstract}
Increasing demand for energy in the world day by day causes the expansion of the electricity network. Technological developments in the energy sector around the world has begun to come to the fore for using highquality enegy in our country, too. At the beginning of these SCADA/DMS applications on electricity distribution network are used. One of the most important functions of the electricity distribution companies is finding the fault location as soon as possible and repairing the fault. However, conventional methods applied by breakdown service prolong outage time, also effectuate danger and damages. Therefore, from production of electric energy to consumption automation solutions are required as SCADA/DMS. In this study, SCADA/DMS system, that will be done application in a distribution company, will be described in a general way. However, remote monitoring of electrical distribution networks, analysis and control will be discussed.
\end{abstract}

Keywords: SCADA/DMS systems, Electricity distribution network, Outage time, Remote monitoring

\section{GíRiş}

Günümüzde enerji hizmetlerinin kaliteli ve sürekli bir şekilde sağlanması, sadece toplumun ve endüstrinin ihtiyaçlarını gidermede değil, ülkelerin uluslararası alanda rekabet güçlerini de belirleyen bir unsur haline gelmiştir. Bu da elektrik üretiminin, iletimin ve dağıtımının güvenli, verimli ve kaliteli olmasını gerektirmektedir. Türkiye'de elektrik dağıtımı ile elektrik üretimi alanlarında liberalleşme ve özelleştirmelerle bu ihtiyaçlara yönelik çalışmalar hızla artmaktadır. $\mathrm{Bu}$ çalışmalar kapsamında elektriğin daha çok kişiye, daha kaliteli, güvenilir ve kesintisiz ulaştırılması için uzaktan izleme, analiz, kontrol işlemlerini yerine getiren SCADA/DMS sistemleri ilk sırayı almaktadır. Ülkemizde elektrik dağıtım sektöründeki özelleştirmeler ve elektriğin perakende satışının başlamasıyla enerji satışında rekabet ortamı oluşmuştur. $\mathrm{Bu}$ durum elektrik dağıtım şirketlerini harekete geçirmiş, bu şirketlere, elektriği kesintisiz, güvenli, kaliteli ve ucuz nasıl satabilirim sorusunu sordurmuş, bu soruya çözüm aratmaya başlatmıştır. SCADA/DMS sistemi bu 
kapsamda müşteriye kesintisiz, güvenli ve kaliteli elektrik sunma imkânı sağlayacaktır.

\section{SCADAIDMS SISTEMLERINE GENEL BAKIŞ}

SCADA/DMS sistemleri elektrik dağıtım şirketleri için son zamanlarda önem arz eden bir konu haline gelmiştir. SCADADMS sistemi dağıtım şirketlerine aşağıdaki nedenlerden dolayı kurulmalıdır:

Mevzuatların getirdiği yükümlülükler;

- Mevzuatlarda SCADAIDMS sistemninin tarif edilmesi ve dağıtım şirketlerine kurma yükümlülüğü getirmesi.

- Yıllık kesinti sayısı ve süresinin mevzuatça belirlenmiş değerlerin üzerine çıkması durumunda müşterileri ödenecek cezaların önüne geçilmesi

- Enerji Piyasası Düzenleme Kurumu yönetmeliklerinde belirtilen verilerin saklanması ve istenilen fortmatta raporların üretilebilmesi

Otomasyon ve ak1llı uygulamalar;

- Arızalara kısa sürede müdahale ve tedarik sürekliliği cezalarının önüne geçilmesi

- Gerçek ve eş zamanlı tüketim trendlerine dayanan yük tahmini yapılabilmesi

Şebekenin uzaktan ve tek noktadan izlenip kontrol edilebilmesi ile daha hılı ve kaliteli hizmet verme imkânı;

- İş gücü ve zaman kazanımı ve ekonomik verimlilik

- Bireylere bağlı olmayan işletme sistematiği

Yukarıdaki sebepler elektrik dağıtım şirketli için SCADAIDMS sistemini zorunlu kılmıştır.

SCADA (Supervisory Control And Data Acquisition), Türkçe'ye "Denetleyicili Kontrol Ve Veri Toplama Sistemi” olarak çevrilebilir.

SCADA geniş bir coğrafyaya yayılmış cihazların bir merkezden bilgisayar aracılığı ile denetlenmesini, izlenmesini, önceden tasarlanmış bir mantık içinde işletilmesini ve geçmiş zamana ait verilerin kaydedilmesini sağlayan sistemlere verilen isimdir. Ayrıca SCADA / DMS modern bir dağıtım kontrol merkezindeki tüm operasyonel faaliyetler için gerçek-zamanlı bilgi sistemidir [1].

Kesin ve gerçek zamanlı bilgi, sistemin işletim ve sürecinin optimizasyonu için gerekli elemanlardır. Bununla birlikte daha verimli, güvenilir ve en önemlisi güvenli işletim sağlanır [2].

SCADA sistemleri büyük bir alana ait teknik konulardaki denetleme ve yönetim işlevini yerine getirmek amacındadır. $\mathrm{Bu}$ bağlamda çoğunlukla HMI (Human-Machine Interface / insan makina arayüzü) veya MMI (Man-Machine Interface) kısaltmaları ile yanyana kullanılır [3].

DMS (Distribution Management System) ise, "Dağıtım Yönetim Sistemi" olarak Türkçe'ye çevrilebilir. Elektrik dağıtım sisteminin izlenmesi ve kontrolü hususunda kontrol merkezinde ve sahada çalışan personellere yardımcı olan karar destek sistemidir [4]. DMS'te yük akışı, kısa devre analizi, topoloji analizi, hata yeri belirleme izolasyon ve servis düzeltmesi, yük tahsisi ve veri tutarlılığı v.s. gibi bir çok fonksiyon kullanılarak şebeke üzerinde gerçek zamanlı veya sanal analizler yapilabilmekte, bu analizler ile şebeke yönetilebilmektedir.

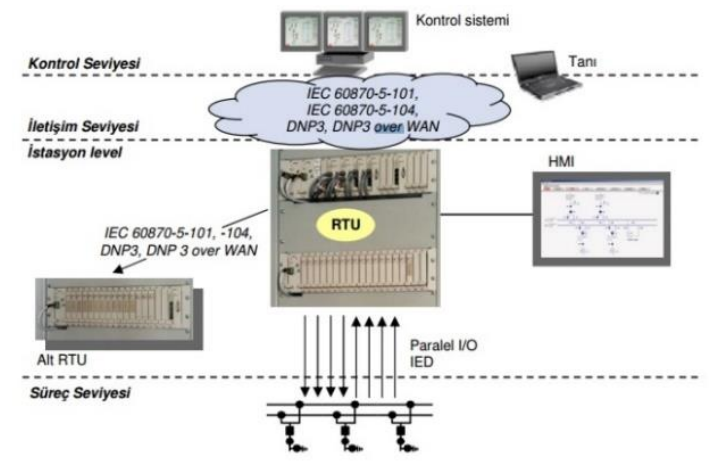

Şekil 1. Dağıtım Şebekesinde Bir Scada Sisteminin Yapıs1

\subsection{Rtu (Remote Terminal Unit)}

Remote Terminal Unit Türkçe'ye uzak uç birim olarak çevrilebildiği gibi yeteneklerine bakıldığında uzaktan izleme ve kontrol ünitesi olarak da çevrilebilir.

RTU'lar bulunmuş olduğu merkezin değişkenlerine ilişkin verileri, toplayan, depolayan, gerektiğinde bu verileri belirli bir haberleşme yolu ile kontrol merkezine gönderen ve kontrol merkezinden gelen komutları uygulayan bir SCADA birimidir [5].

SCADA sistemi içerisinde yerel ölçüm ve kumanda noktaları oluşturan RTU'lar birbirlerine bağlanabilen çeşitli cihazları, kesicileri ve ayırıcıları kumanda edebilir. Ölçülmesi gereken akım, gerilim, aktif ve reaktif güç gibi değerleri ölçebilir. Ayrıca ayırıcı, kesici durumlarını da kontrol edebilme imkânı sağlar. RTU yardımıyla merkezi kumanda ve izlemeyi sağlamak için RTU'lar, ölçüm sonuçları ile çalışma durumlarını merkeze ileterek merkezden 
gelen komutlar doğrultusunda işlemleri gerçekleştirir. Böylece merkezi denetim birimlerinin başında bulunan operatörün tüm ölçüm sonuçlarını görmesini ve gerekli komutları göndererek sistemin denetlenmesini sağlar. Fakat RTU'nun görevi sadece ölçüm yapmak ve komut uygulamak değil ölçüm sonuçlarının belli sınırlar içinde olup olmadığını denetleyerek aykırı yada alarm durumlarını merkeze bildirir [5]. RTU'lar kullanıcının özel isteklerini yerine getirebilecek şekilde programlanabilir. Böylece denetleyici cihazların kullanıcı gereksinimlerini karşılayacak şekilde sağlanmış olur. $\mathrm{Bu}$ esnada diger RTU'larla haberleşerek işlemlerin yerine getirilmesini sağlamış olur. Birbirleri arasındaki iletişimi sağlarken aynı zamanda merkezi birim tarafından sürekli gözetlenerek sistemin tümünün denetlenmesine izin verirler [6].

\section{BİR ELEKTRIKK DAĞITIM ŞİRKETINDE BITTIM \\ AŞAMASINDA OLAN SCADA/DMS PROJESININ INNCELEMESİ}

$\mathrm{Bu}$ elektrik dağıtım şirketinde SCADA/DMS projesi kapsamında 96 dağıtım merkezinde çalışma yapılmıştır. Bu dağıtım merkezlerinden 46 adedine ADM (Ana dağıtım merkezi) özellikli sistem, 50 adedine ise FOÜ (Fider otomasyon Ünitesi) özellikli sistem kurulmuştur. ADM özellikli dağıtım merkezlerinde TM1703 ACP yüksek donanımlı RTU, FOÜ özellikli dağıtım merkezlerinde ise TM 1703 emic RTU kullanılmıştır. Koruma Röleleri olarak ise Siemens SIPROTEC 7SJ62 marka koruma röleleri kullanılmıştır.

$\mathrm{Bu}$ projede dağıtım şebekesinin durumu göz önüne alınarak ana kontrol merkezi ve acil kontrol merkezi olarak iki adet kontrol merkezi kurulmuştur. Yangın, Doğal afet, haberleşme kesintisi v.b gibi durumlarda Ana kontrol merkezi devre diş1 kaldığında Acil durum kontrol merkezi ana kontrol merkezinin görevini üstlenecektir.

SCADA/DMS sistemlerinde arayüz programı operatörün iletişim konsolu yoluyla güç sistemiyle haberleşmesi için kullanılan programdır. $\mathrm{Bu}$ program vasitasıyla sahadaki RTU'larla haberleşilmekte, saha ekipmanları kontrol edilebilmekte, sahadaki ölçüm cihazlarından bilgi alınabilmekte ve saha analizleri yapılabilmektedir. $\mathrm{Bu}$ projede Siemens A.ş.'nin geliştirmiş olduğu Spectrum Power 4 arayüz programı kullanılmıştır. Aşağıda Spectrum Power 4 ekran görüntüleri yer almaktadır [7]:

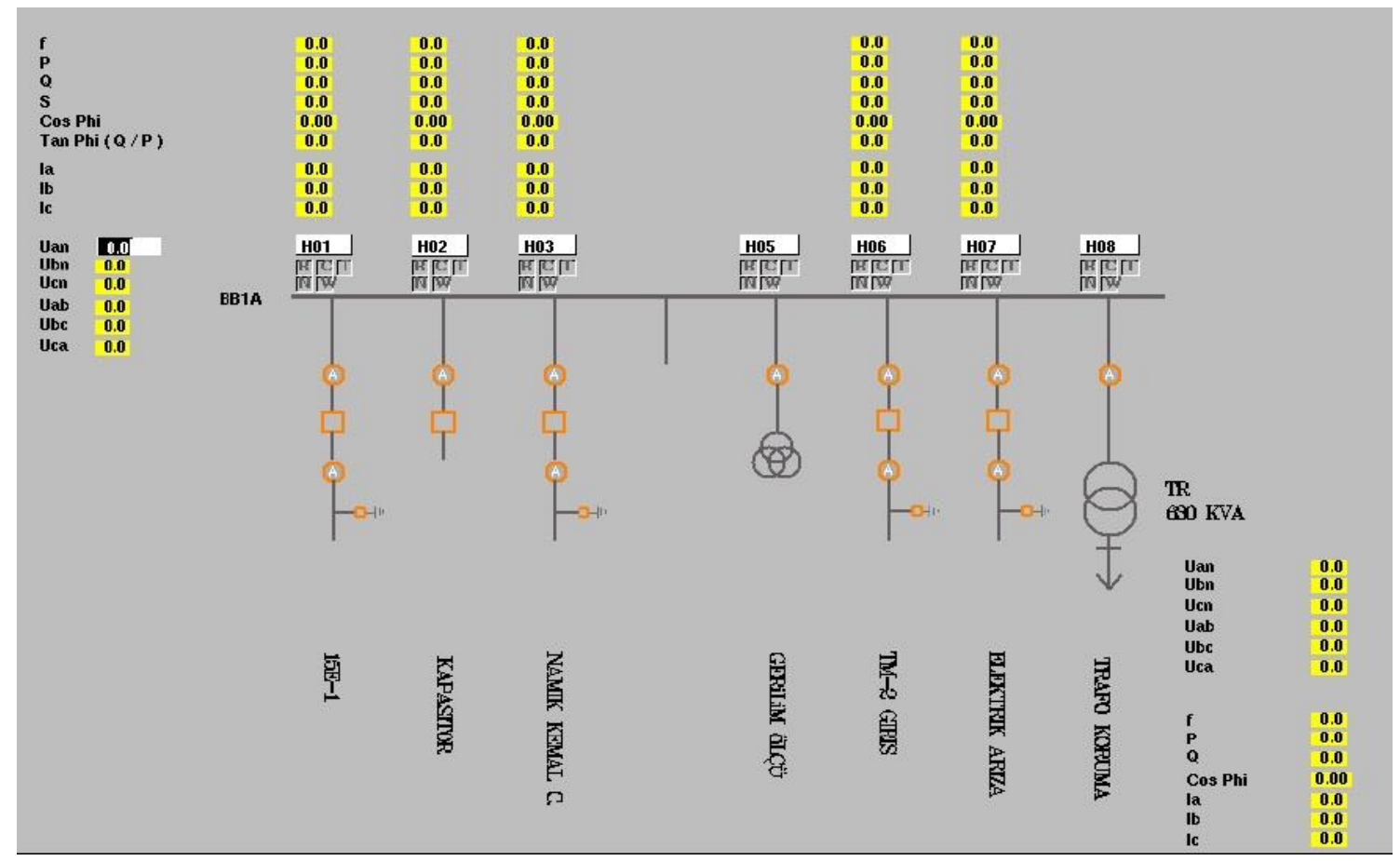

Şekil 3. Spectrum Power 4 Ekran Görüntüsü 


\section{TEKNIIK KALITE IZLEME VE SCADAIDMS ENTEGRASYONU}

$\mathrm{Bu}$ bölümde SCADAIDMS projesi incelenen elektrik dağıtım şirketinde bulunan teknik kalite izleme sistemi ile SCADAIDMS sisteminin nasil entegre edilebileceği üzerinde çalışılmıştır.

Teknik kalite izleme sisteminde trafo merkezlerindeki fiderlere UMG 96 RM enerji analizörü takılarak ölçümler izlenmektedir. $\mathrm{Bu}$ analizör ile gerilim, akım, aktif, reaktif, görünür güçler, güç faktörü, frekans, 40. dereceye kadar ara harmonikler ve flickrlar ölçülüp kaydedilmektedir. Bunların yanında fider açmaları ve gerilim dengesizlikleri de analizörden alınabilmektedir. Şekil 5'te akım ve gerilimdeki dengesizliklerden ötürü oluşmuş olay görülmektedir.

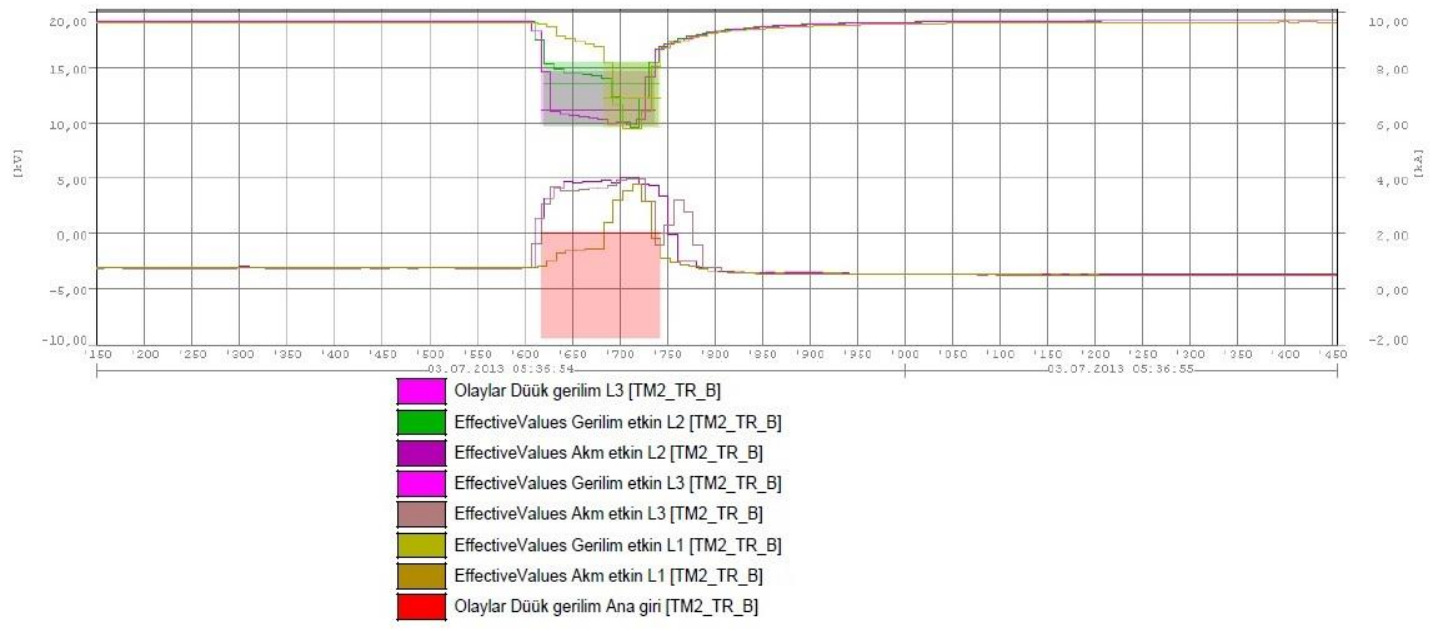

Şekil 5. Örnek Olay Çıktısı

Şekil 5'teki grafikte sol taraf gerilim sağ taraf ise akımı belirtmektedir. Yukarı gerilim salınımı, aşağısı ise akım salınımıdır. $600 \mathrm{~ms}$ 'de gerilim $19 \mathrm{kv}$ civarından $9 \mathrm{kv}$ civarına düşmüş, akım ise $0,5 \mathrm{kA}$ düzeyinden $4 \mathrm{kA}$ düzeyine yükselmiştir. Bu durum devrede bir kısa devre oluştuğunu göstermektedir. Arıza 200 ms sürmüş $800 \mathrm{~ms}$ 'de düzelmiştir. Bu durum 1sn'den az sürdüğü için mevzuatta geçici kesinti olarak geçmektedir. SCADAIDMS sistemi sayesinde bu geçici kesintiler tespit edilecektir. Dağıtım şirketinin şebekesinde bu kesintilerin mevzuatta belirlenen süre ve sayıları geçmesi durumunda müşterilere tazminat ödemesi gerekecektir.

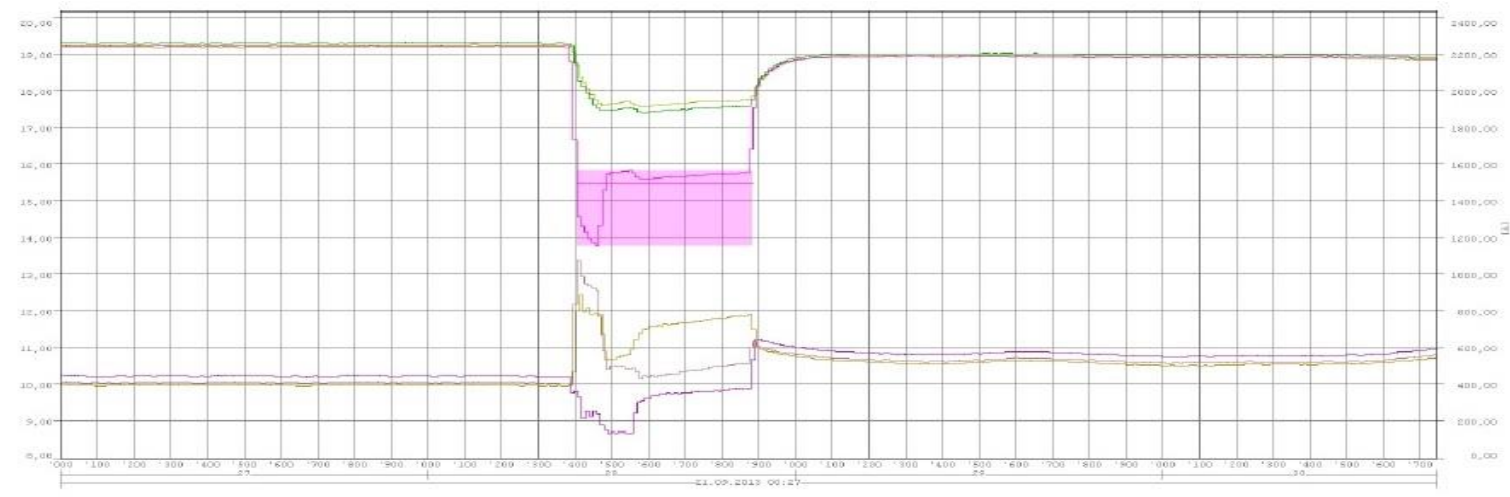

Olaylar Dưūk gerilim L3 [KILAVUZLU_TR_B] EffectiveValues Gerilim etkin L1 [KILAVUZLU_TR_B] EffectiveValues Akm etkin L1 [KILAVUZLU_TR_B] EffectiveValues Gerilim etkin L3 [KILAVUZLU_TR_B] EffectiveValues Akm etkin L3 [KILAVUZLU_TR_B] EffectiveValues Gerilim etkin L2 [KILAVUZLU_TR_B] EffectiveValues Akm etkin L2 [KILAVUZLL_TR_B]

Şekil 6. Örnek Olay Çıktısı 
Şekil 6'daki olay çıktısında ise 400 ms'de L1 ve L2 gerilimi $19 \mathrm{kv}$ düzeyinden $17.5 \mathrm{kv}$ düzeyine, L3 gerilimi ise düşük gerilim seviyesine yani $14 \mathrm{kv}$ düzeyine düşmüştür. L2 fazında akım, fazlardaki geriliminin düşmesiyle düşmüştür. Fakat oluşan kısa devre L1 ve L3 fazlarını etkilemiş ve 400A düzeyinde seyreden akım L1 fazında 900A, L3 fazında ise1100A düzeyine yükselmiştir. $900 \mathrm{~ms}$ 'de akım düzelmiş fakat dalgalanma devam etmiştir. $\mathrm{Bu}$ da 500ms sürdüğü için geçici kesinti olarak kayıtlara geçmiştir.

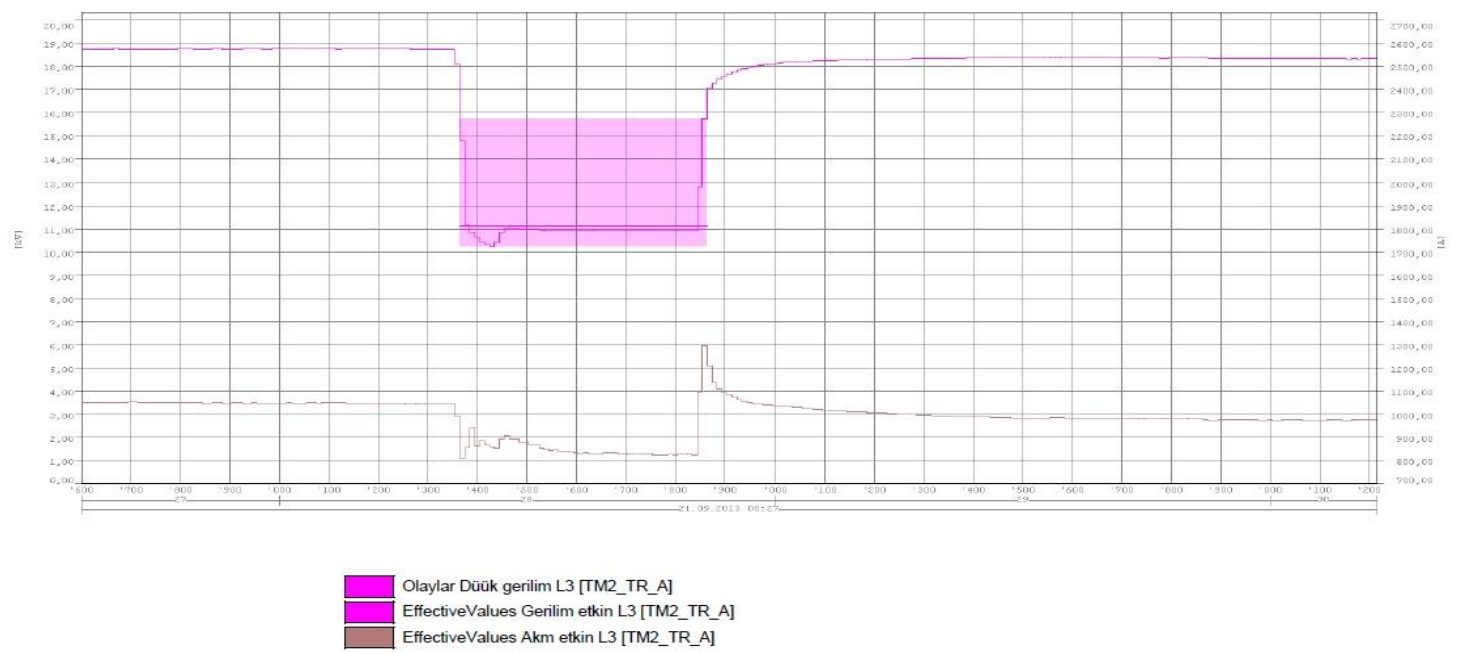

Şekil 7. Olay Çıktı Görüntüsü

Şekil 7'de ise Şekil 6'daki olaydan etkilenen diğer baranın grafiği görülmektedir. Şekil 7'deki grafikte baranın durumu normal olduğu için (kısa devre yok) gerilim düşümü akımı da düşürmüştür.

Teknik kalite sisteminin verilerini çekip onları değerlendirebilmek için SCADA/DMS arayüz programında bu değerlerin gösterilebileceği bir form oluşturulması gerekmektedir. Bu çalışmada teknik kalite izleme sisteminin veritabanı yapısı SCADA/DMS arayüz programının anlayabileceği hale getirilmiş ve teknik kalite izleme sistemi entegrasyona hazır hale gelmiştir.

Teknik kalite izleme sisteminin veritabanı yapısını sistemi kuran firma bildiği için bu yapı hakkında firmadan bilgi alınmıştır. Bu bilgiler ışı̆̆ında database yapısı incelenmiş SCADA/DMS sisteminin anlayabileceği hale getirebilmek için tablo birleştirmeler yapılarak kod oluşturulmuştur.

Entegrasyon için gerekli kodlar hazırlanmış SCADA/DMS sisteminin anlayabileceği veri yapısı oluşturulmuştur. Bu kodlar vasıtasıyla SCADA/DMS, veri tabanından akım, gerilim, aktif, reaktif, görünür güç, güç faktörü gibi değerleri analizör bulunan fiderler bazında çekebilecek bu değerler üzerinden analiz yapabilecektir. Böylece izleme sistemi ile SCADA/DMS izleme sisteminin entegrasyonu sağlanmış olacaktır.

\begin{tabular}{|c|c|c|c|c|c|c|}
\hline & Row & TrafoMerkezi & Trर्वfo & Fider & tag_name & value \\
\hline 1 & 1 & KILILI TM & KILILI TRA & F-1 KAHRAMANMARAS & Van & 19.10 \\
\hline 2 & 2 & KILILI TM & KILILI TRA & F-1 KAHRAMANMARAS & Von & 19.18 \\
\hline 3 & 3 & KILILI TM & KILILI TRA & F-1 KAHRAMANMARAS & Von & 19.12 \\
\hline 4 & 4 & KILILI TM & KILILI TRA & F.1 KAHRAMANMARAS & la & 79.23 \\
\hline 5 & 5 & KILILI TM & KILILI TRA & F.1 KAHRAMANMARAS & lb & 81.30 \\
\hline 6 & 6 & KILILI TM & KILILI TRA & F.1 KAHRAMANMARAS & lc & 76.22 \\
\hline 7 & 7 & KILILI TM & KILILI TRA & F-1 KAHRAMANMARAS & P & 4.48 \\
\hline 8 & 8 & KILILI TM & KILILI TRA & F-1 KAHRAMANMARAS & $Q$ & 0.63 \\
\hline 9 & 9 & KILILI TM & KILILI TRA & F.1 KAHRAMANMARAS & S & 4.53 \\
\hline 10 & 10 & KILILI TM & KILILI TRA & F.1 KAHRAMANMARAS & GucFaktoru & 0.99 \\
\hline
\end{tabular}

Şekil 8. Kod Çıktısı

\section{ELEKTRİK DAĞITIM ŞEBEKESİ İÇİN SCADA/DMS FAYDALARI}

Scada/Dms projesi bölgede faaliyet gösteren dağıtım şirketi için öncelikli olarak manevra kabiliyeti yüksek olan dağıtım merkezleri ve büyük güç çeken müşterilerin beslendiği merkezler gibi önem arz eden kritik bölgelere kurulmuştur. $\mathrm{Bu}$ kritik merkezlere Scada/Dms sistemi kurulmadan önce, bu merkezlerde bir kesinti olduğunda, kesinti müşterinin aramasıyla anlaşılabilmekteydi. Daha sonra kesintinin olabileceği bölgeler analiz edilip ekip gönderilmekte, ekip, arızayı giderene kadar alternatif besleme yapmak için ring şebekelerde manevra yapıp müşteriye geçici olarak enerji vermekteydi. Arıza giderildikten sonra tekrar müşteriye normal şekilde enerji verilmekteydi. Bu şekilde bir 
çalışmayla müşterinin kesinti süresi uzamakta, dağıtım şirketi satabileceği enerjiyi satamamaktayd. Scada/Dms'in kurulmasıyla kesinti bilgisi müşteri aramasına gerek kalmadan merkeze ulaşmakta ve sistem alternatif besleme şekillerinin analizini merkezde bulunan operatöre çıkarabilmektedir. Bu vesileyle ekip oraya ulaşmadan kesinti olduğu anda uzaktan manevra yapılıp müşteriye kısa sürede enerji verilebilmektedir. Ekip arıza noktasına ulaşıp arızayı giderdikten sonra müşteriyi normal şekilde beslemektedir. Böylelikle müşteriye zaman kaybetmeden enerji verilebilmektedir.

\section{SONUÇ}

$\mathrm{Bu}$ çalışmada SCADAIDMS sistemleri incelenmiş olup Adıyaman Kahramanmaraş Bölgesinde faaliyet gösteren bir dağıtım şirketinin SCADAIDMS projesi incelenmiş olup faydaları çıkarılmıştır. Bunun yanında bu dağıtım şirketinde mevcutta kurulu olan teknik kalite izleme sisteminin SCADAIDMS ile nasil entegre olabileceğinin üzerinde durulmuştur.

Sonuç olarak elektrik dağıtım tesislerinde kullanılan SCADA/DMS sistemleri, kompanzasyon ve teknik kalite izleme sistemleri mevcut tesislerin verimli işletilmesini ve buna dayanarak bu alana yapılacak yatırımların ertelenmesini ve geleceğe yönelik etkin planlamaların yapılmasını sağlamaktadır.

\section{KAYNAKLAR}

[1]. Abb., 2009. Network Manager SCADA/DMS. 1-8. URL(erişim tarihi 03.05.2014) http://www05.abb.com/global/scot/scot221.nsf/verit ydisplay/d812ff32efa92201852575fa00562955/\$file/ BR_SCADA_DMS.pdf

[2]. Özkara, A.,2009. Bir Orta Gerilim Dağıtım Sistemi Modelinin Scada ile İzlenmesi. Yüksek Lisans Tezi. İstanbul Teknik Üniversitesi Fen Bilimleri Enstitüsü. İstanbul. 48s.

[3]. Wikipedia., 2013a SCADA. URL (erişim: 10.10.2013). http:// tr.wikipedia.org/wiki/SCADA

[4].Wikipedia., 2013b Distribution Management System. URL (erişim: 10.10.2013). http://en.wikipedia.org/wiki/Distribution_manageme nt_system

[5]. Yücel, A., 2005. Elektrik Dağıtım Şebekeleri İçin Scada Sistemlerinin İncelenmesi ve Bir Bölge Uygulamasının Bilgisayar Ortamında Yapılmas1. Yüksek Lisans Tezi. Marmara Üniverisitesi Fen bilimleri Enstitüsü. İstanbul. 99s.

[6]. Anonim.2014b. SCADA Sistemlerinin Genel Yap1s1. URL (erişim: 02.03.2014).http://www.ozeldersin.com/scadasistem-yazisi.html

[7]. Siemens AG., 2013. SCADA\&BASIDI

Design. Nürnberg. 50s. 